\title{
A case of pulmonary alveolar microlithiasis
}

\section{BMAC Balasuriya, ${ }^{1}$ SAM Kularatne ${ }^{2}$, and N Ratnatunge ${ }^{3}$}

(Index words: Haemoptysis, heavy lungs, pulmonary radiological opacities)

We report here a case of multiple radiological lung opacities with breathlessness and haemoptysis which turned out to be pulmonary alveolar microlithiasis (PAM).

A 41-year old man was admitted to the Teaching Hospital, Peradeniya on 3 May 2003 with a history of cough, chest pain and increasing breathlessness for one week. He had a history of several similar episodes during the past 18 months. A lung biopsy done earlier suggested pulmonary alveolar microlithiasis. Tuberculosis and malignancy had been excluded.

On admission he had a respiratory rate of $18 / \mathrm{min}$, and reduced chest expansion. There was no cyanosis or digital clubbing. Auscultation revealed diffuse, fine inspiratory crackles, symmetrically distributed over both lung fields. The cardiovascular, abdominal and central nervous system examinations were normal.

The chest radiograph showed diffuse high density micronodules and reticular lines that obliterated the bronchovascular bundles, the margin of the heart and the diaphragm (Figure 1). On the second day of admission he developed massive haemoptysis, became severely hypoxaemic and died despite attempts at resuscitation. At autopsy the lungs were found to be heavy $(5 \mathrm{~kg})$ with a multitude of small stones scattered in both lungs. Bilateral pulmonary apical haemorraghes were also noted. There was no calculous disease in the other organs. Microscopic examination of the lungs showed focal haemorraghes, septal arteriolar medial hypertrophy and

${ }^{1}$ Registrar, ${ }^{2}$ Physcian, Teaching Hospital and ${ }^{3}$ Professor in Pathology Faculty of Medicine, Peradeniya.

Correspondence: SAMK, Department of Medicine, Faculty of Medicine, University of Peradeniya, Sri Lanka. Tel: 00948 388368, fax 00948 232343, e-mail:<samkul@sltnet.lk> (Competing interests: none declared). Received 10 June and accepted 10 July 2004. 


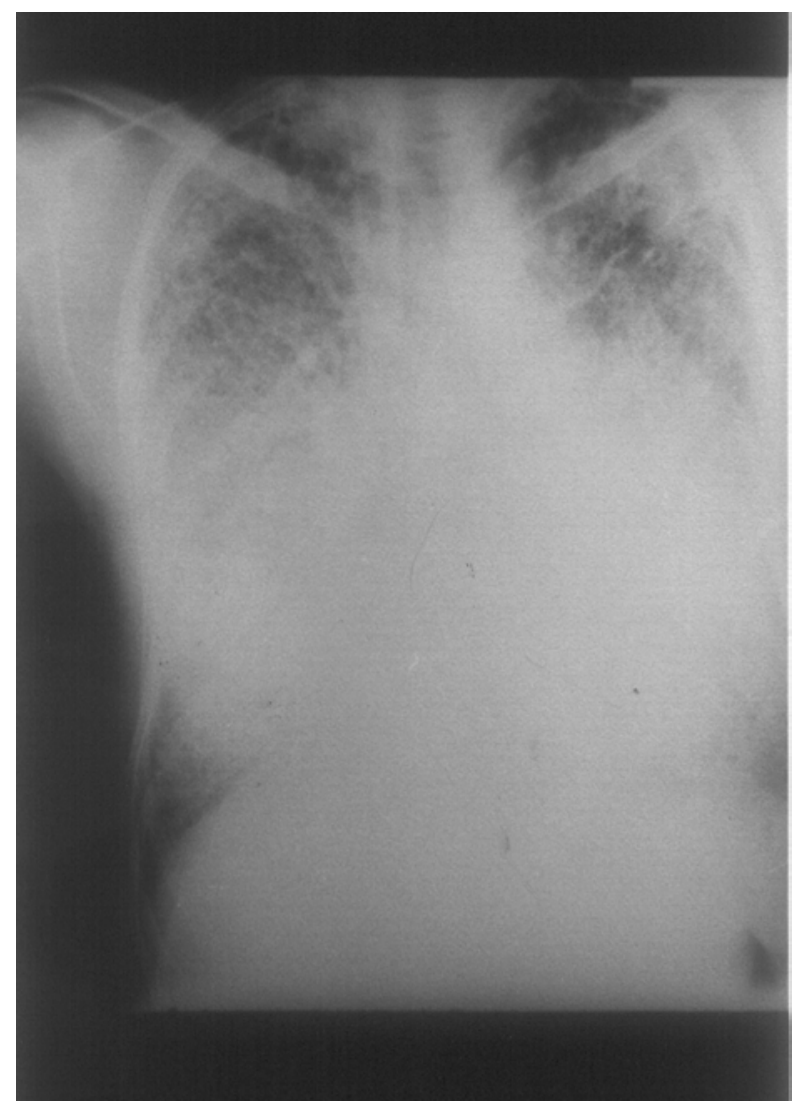

Figure 1. Chest $\mathrm{X}$-ray showing high density opacities and reticular lines.

intra-alveolar deposits of concentrically laminated calcific bodies (Figure 2). These findings confirmed the diagnosis of pulmonary alveolar microlithiasis.

The patient had a long history of chest symptoms. The lungs were studded with tiny stones making them heavy. PAM is a rare disease characterised by widespread calcific intra-alveolar concretions in both lungs [1]. Although the cause of PAM is still unknown, an autosomal recessive inborn error of metabolism of calcium and phosphate has been suggested. The diagnosis is usually confirmed by high resolution $\mathrm{CT}$ and transbronchiolar biopsy [2]. The disease has a slowly progressive protracted course.

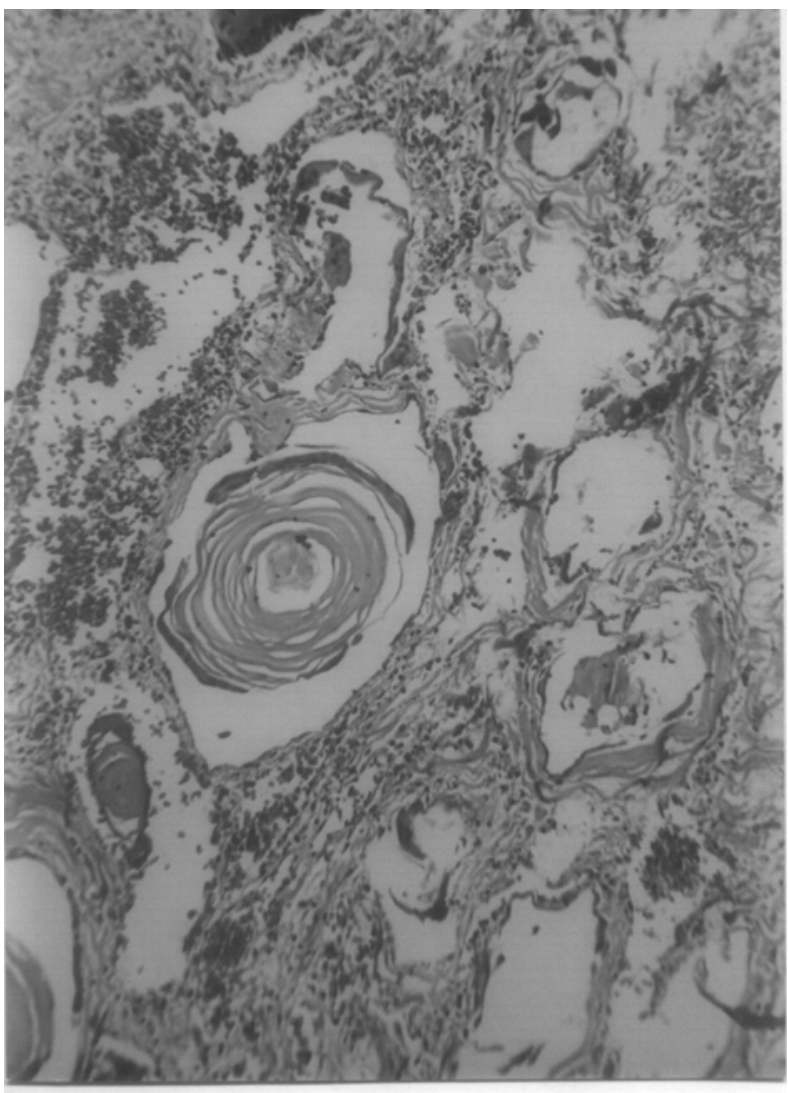

Figure 2. Lung histology showing intra-alveolar concentrically laminated calcific bodies.

Disodium etidronate, which is known to inhibit microcrystal growth of hydroxyapatite, is used as therapy in PAM. It should be continued over one year to monitor the regression of calcific densities in the chest radiographs and high resolution CT. Early treatment may retard the progression of PAM.

\section{References}

1. Harbitiz F. Extensive calcification of lungs, a distinct disease. Archives of Internal Medicine 1918; 21: 139-41.

2. Sosman MC, Dodd GD, John WD. The familial occurrence of pulmonary alveolar microlithiasis. American Journal of Roentgenology 1959; 77: 947-1012. 